\title{
Urgences
}

\section{Errances (extraits)}

\section{James Paulin}

Numéro 5, 3e trimestre 1982

URI : https://id.erudit.org/iderudit/025076ar

DOI : https://doi.org/10.7202/025076ar

Aller au sommaire du numéro

Éditeur(s)

Urgences

ISSN

0226-9554 (imprimé)

1927-3924 (numérique)

Découvrir la revue

Citer ce document

Paulin, J. (1982). Errances (extraits). Urgences, (5), 45-50.

https://doi.org/10.7202/025076ar

Ce document est protégé par la loi sur le droit d'auteur. L'utilisation des services d'Érudit (y compris la reproduction) est assujettie à sa politique d'utilisation que vous pouvez consulter en ligne.

https://apropos.erudit.org/fr/usagers/politique-dutilisation/
Cet article est diffusé et préservé par Érudit.

Érudit est un consortium interuniversitaire sans but lucratif composé de l'Université de Montréal, l'Université Laval et l'Université du Québec à Montréal. Il a pour mission la promotion et la valorisation de la recherche. https://www.erudit.org/fr/ 
JAMES PAULIN

\section{Errances}

(Extraits) 


\section{UNE PAIX}

Une paix de cadavre

en appel

une terre de vides

et de peines

les blés jonchent

et jaunissent

les ombres déambulent

absentes

cette terre frissonne

désertée

dans son corps de glace

inhabité

les spectres investissent

impériaux

durant tes durs sommeils

impérieux

Là où le chêne oublie ses racines

de plomb

tout contre sa quête

de l'espoir

la côte écoute ses humeurs

malgré ton pas nonchalant

le pays respire ses hivers

envers ton regard distrait

Le désert I'abandon I'exil

conjuguent le sort à l'indifférence

la contrée s'endort syntaxée

dans le rêve d'enfants arrachés

à peine le soleil se lève-t-il

que déjà l'aube s'évache

I'horizon s'encrasse de l'Ouest

de brumes d'acides de crevasses 
Terre désespérante

cernée d'arêtes d'Appalaches

marquée aux tristes cratères de Lune

sablée aux champagnes de l'ennui

sur toi plus jamais les sueurs du sang

ne laissent de traces

ilôt puéril d'Amérique cariée

tu oublies jusqu'à l'idée du coeur

l'autochtone qui coule en tes veines

tu nies dans toutes tes hypnoses

cette forêt-soeur qui te givre les lèvres

cette guerre d'usure t'avale la vie jusqu'à la moelle de la femme rêvée tes enfants se meurent écartelés avant même l'ouverture des paupières sur la béance de ta blessure

Dans l'océan des mièvres prophètes ta terre est aux enchères et le fleuve distille d'amertume toutes ses fièvres délétères Dors! dors sur ta couche de misère un miracle viendra en ton absence glaner dans les creux de ton Histoire la fable oiseuse de ton existence

Dans quel lit de mensonges peut donc cheminer ta rivière vers quel absurde chemin s'engouffre ta sombre lumière toi seule le sais Atlantide perdue toi seule s'y rendras alors que j'essaierai d'oublier la souffrance qui perce de front mon âme 


\section{NAISSANCE}

Et la lumière s'éclate en millions d'atomes sur la glace plane des temps bredouilles où se macère acide l'ère des grandes fouilles où I'Amour demeure du reste Roi

Ce pays est né Et selon nous d'une tare céleste à l'esprit mutin à l'endroit même où il est mort de nous comme pour maudire l'état malin qui fit de lui l'octobre-misère des us et naguères fuyant l'opalin

Comme dans les savoirs totémiques gravés sur la peau des troncs nus l'échelle des rêves chimériques lévite impassible et tue comme nuée volage sur Terre toute ronde encore et meuble

Du Loup comme de I'Ourse soeur le souvenir du sang s'esquisse comme pour ourdir du coeur de la peur l'idée même d'une contrée "en câlisse" Vase d'or même d'où sublime l'Essence d'où l'on a scellé érotique le pacte baignant dans le pourpre-lune de l'Hymen

Le mépris a fondu son noir sur blanc sans l'horreur des guerres résonnantes sans la mort des tares raisonnantes de lui-même bête s'est ouvert le flanc d'où putrides coulent les humeurs sui genesis 
Traqué horrifié dans son palais de glaces

le jour par revers goûte le fruit du pervers

qui déjà dort son sommeil sous l'hiver

chez l'État des dieux se baisant de face

Victoire dit-il se dit-il puéril

comme défaite pleure-t-il se pleure-t-il

cambré toujours sur le métronome

où s'achève encore sans fin le coeur de l'Homme

Mais Grand Dieu du fond d'images incrédule

d'espoirs l'espoir paysan le lui souffle

du Tertre où le confine sa solitude

d'où monte le parfum sauvage d'une plénitude

germinée d'un Fleuve "en calvaire"

vers le mont chauve d'un volcan royal

où crucifiée sa lumière se réverbère

en cascades hors le temps du maquis pénal

dans l'ère sans doute encore des marchés vénaux

où la vertu maudite des parcheminés du fric

éventrent encore la foi de l'enfant-vestale

sur l'autel de fer de jésus bio-troniques

Indivis incarné le mystique mystère souffre son espoir sa charnelle matière et "De profundis" clame son désarroi devant l'imprimé en faisant folle foi

Ce pays est né et qu'en crève l'Étroit aux calendes juliennes foi d'apostat sur le début d'un cas la fin d'un " $K$ " de l'Amour débile d'un ventre nubile comme loi blanche d'un instinct de sur-vie

La Parole n'en pouvant plus a dû ouvrir au sabre sa sphère sans autre serment imprévu que le baiser du Sphinx l'ère des calendriers déchirés 


\section{COINCÉ}

Coincé entre la proximale souvenance

et mon futur à pied-de-nez

j'ai le regard qui s'incrédulise jusqu'à la nuit qui tombe dans le tintamarre et le tohu-bohu du soleil des piétons

Je garde mon attaché dans le sillage des jets et quelques mots connus ... sésames brûlant de feu judas des portes closes

J'ai rêvé d'ún pays

qui déjà était

profondément enfoui en sa matière j'ai rêvé le futur de l'enfant qu'on allaite

"Je vous entends demain parler de Liberté"

Vous me faites demain

I'Amour des sourires lointains et je vous dis ce soir ce qui s'est fait hier 